\title{
Mal-estar docente e inclusão: uma revisão bibliográfica a partir de teses e dissertações da CAPES
}

\author{
Teacher malaise and inclusion: a bibliographic review based on CAPES theses and dissertations \\ Malestar docente e inclusión: una revisión bibliográfica basada en tesis y disertaciones de CAPES
}

Isabella Balducci Rezende

ORCID: https://orcid.org/0000-0001-6091-9869 Universidade Federal de Itajubá, Brasil E-mail: isabellabalduccir@outlook.com

Juliani Flávia de Oliveira

ORCID: https://orcid.org/0000-0003-4869-2651 Universidade Federal de Itajubá, Brasil E-mail: juliani_flavia@hotmail.com

Denise Pereira de Alcantara Ferraz

ORCID: https://orcid.org/0000-0002-1491-5741 Universidade Federal de Itajubá, Brasil E-mail:deferraz@unifei.edu.br

\begin{abstract}
Resumo
O presente artigo decorre de pesquisa que teve por objetivo analisar os trabalhos que investigam a relação entre malestar docente e a inclusão dos alunos público-alvo da educação especial (PAEE). Esta foi uma pesquisa de caráter qualitativo, com elementos da pesquisa do tipo estado da arte que buscou teses e dissertações dentro catálogo de teses e dissertações da CAPES que tratassem de mal-estar docente e a inclusão de alunos PAEE. Os trabalhos selecionados foram analisados de forma a mostrar quais foram as metodologias e referenciais teóricos adotados, bem como criadas quatro categorias para análise dos resultados e discussões dos trabalhos: 1) más condições de trabalho; 2) angústias e frustrações; 3) formação de professores; 4) solução/resposta dada sobre o mal-estar. As categorias mostraram elementos de queixas que dizem respeito às condições de trabalho, às suas respectivas formações e, aos motivos dos seus sofrimentos, além da busca de soluções e respostas que explicassem esses sofrimentos. Os resultados mostraram, ainda, que existem lacunas na produção científica acerca do tema de mal-estar docente relacionado à inclusão, bem como mostrou indícios da fragilidade e inconsistência da formação de professores no que tange à inclusão de alunos com deficiência. Considera-se, com as análises, que a educação inclusiva precisa ser ressignificada por professores, se apropriando de laços livres de preconceito e ações narcisistas.
\end{abstract}

Palavras-chave: Mal-estar docente; Inclusão escolar; Revisão bibliográfica; Catálogo de teses e dissertações.

\begin{abstract}
This article aims to analyze the works that investigate the relationship between teacher malaise and the inclusion of students as a target audience of special education. This was a qualitative research with state-of-the-art research elements that sought theses and dissertations within the CAPES theses and dissertations catalog that dealt with teacher malaise and the inclusion of students as a target audience of special education. The selected works were analyzed in order to show which methodologies and theoretical references were adopted, as well as four categories were created to analyze the results and discussions of the works: 1) poor working conditions; 2) anxieties and frustrations; 3) teacher training; 4) solution/answer given about the malaise. The categories showed elements of complaints related to working conditions, their respective backgrounds and the reasons for their suffering, in addition to the search for solutions and answers that would explain these sufferings. This article showed that there are still gaps in the scientific production on the topic of teacher malaise related to inclusion, as well as showing signs of weakness and inconsistency in teacher education regarding the inclusion of students with disabilities. It is considered with the analyzes that inclusive education needs to be resignified by teachers appropriating ties free from prejudice and narcissistic actions.
\end{abstract}

Keywords: Teacher malaise; School inclusion; Literature review; Theses and dissertations catalog.

\section{Resumen}

Este artículo tiene como objetivo analizar los trabajos que investigan la relación entre el malestar docente y la inclusión de los estudiantes como público objetivo de la educación especial. Se trató de una investigación cualitativa con elementos de investigación de vanguardia que buscó tesis y disertaciones dentro del catálogo de tesis y 
disertaciones de CAPES que abordaron el malestar docente y la inclusión de estudiantes en el público objetivo de educación especial. Los trabajos seleccionados fueron analizados con el fin de mostrar qué metodologías y referencias teóricas se adoptaron, así como se crearon cuatro categorías para analizar los resultados y discusiones de los trabajos: 1) malas condiciones laborales; 2) ansiedades y frustraciones; 3) formación de profesores; 4) solución / respuesta dada sobre el malestar. Las categorías mostraron elementos de denuncias relacionadas con las condiciones de trabajo, sus respectivos antecedentes y los motivos de su sufrimiento, además de la búsqueda de soluciones y respuestas que expliquen estos sufrimientos. Este artículo mostró que aún existen vacíos en la producción científica sobre el tema del malestar docente relacionado con la inclusión, además de mostrar signos de debilidad e inconsistencia en la formación docente en cuanto a la inclusión de estudiantes con discapacidad. Se considera con los análisis que la educación inclusiva necesita ser resignificada por docentes apropiándose de vínculos libres de prejuicios y acciones narcisistas.

Palabras clave: Malestar docente; Inclusión escolar; Revisión bibliográfica; Catálogo de tesis y disertaciones.

\section{Introdução}

Almejando a construção de uma sociedade inclusiva, na qual todas as pessoas são valorizadas e exercem os seus direitos de cidadania, compreende-se que os espaços escolares são caminhos para a concretização desse ideal, o que implica, necessariamente, a organização de ambientes educacionais que não admitam atitudes de discriminações e preconceitos para com o outro.

Nesta perspectiva, a educação especial, que historicamente se configurou como um sistema paralelo ao sistema regular de ensino, caminha no sentido de inserir-se como parte desse sistema, o que pode ser evidenciado pelas sucessivas normatizações oficiais que assegurem a matrícula dos alunos público-alvo da educação especial (PAEE) em classes comuns do ensino regular (Brasil, 1988, 1996, 2001, 2008).

Dentre os marcos legais mais recentes, destacam-se a Política Nacional de Educação Especial na Perspectiva da Educação Inclusiva de 2008 (Brasil, 2008) e o Decreto n 7.611, de 17 de novembro de 2011 (Brasil, 2011). Estes documentos estabelecem o cômputo da dupla matrícula de alunos com deficiência, transtornos globais do desenvolvimento e altas habilidades/superdotação, bem como estabelece o atendimento educacional especializado (AEE) complementar ou suplementar ao ensino regular, a ser fornecido por um professor "especializado" em salas de recursos multifuncionais (SRM) e dá outras providências.

Por efeito destas preconizações legais, um número crescente de alunos PAEE vem conquistando os espaços escolares, a julgar pelos dados do Censo da Educação Básica que, no ano de 2020, registrou um total de 1,3 milhão de matrículas desse alunado nos sistemas de ensino, o que representou um aumento de 34,7\% das matrículas registradas no ano de 2016 (Brasil, 2021).

Com seus direitos garantidos e assegurados pela legislação brasileira, as pessoas com deficiência puderam exercer seus direitos educacionais dentro da sala de aula regular e, assim, tornou-se necessário que professores e gestores entendam que são necessárias mudanças de posturas e a aquisição de novos conhecimentos que possam garantir a inclusão dos alunos PAEE.

Entretanto, a conquista do acesso dos alunos PAEE aos espaços que historicamente lhes foram negados carrega consigo a necessidade de enfrentamento dos numerosos obstáculos colocados pelos contextos da educação brasileira, tais como: a falta generalizada de recursos, o uso de metodologias de ensino centradas no professor, a precarização da carreira docente e professores cujos processos formativos apresentam-se defasados no que se refere ao preparo para a atuação com a diversidade do PAEE (Carvalho, 2019).

Diante destas atuais demandas, Kupfer e Bastos (2010) discutem que o processo de inclusão escolar não pode ser feito sem a inclusão, também, dos professores. Dessa forma, acredita-se ser importante abrir a escuta também para a voz do professor que atua com este grupo nas classes regulares. 
A escolha de uma profissão, bem como o seu exercício, conduz um indivíduo a diferentes graus de satisfação profissional com relação ao que exerce. A expressão mal-estar docente diz respeito a sentimentos de desmotivação, desmoralização ou desencanto que pode cercar os professores diante das diversas exigências a ele atribuídas (Picado, 2009). Outra expressão comumente encontrada é a expressão sofrimento psíquico. Xavier, Nunes e Santos (2008) relacionam a expressão sofrimento psíquico ao conceito de Codo (1999) de Síndrome de Burnout. O Burnout é "um problema, uma síndrome que afeta principalmente os trabalhadores encarregados de cuidar (caregivers)" (Codo \& Vaques-Menezes, 1999, p. 2). Essa expressão diz respeito a uma síndrome em que o sujeito perde o sentido relacional com o seu trabalho e afeta, principalmente, sujeitos que possuem contato direto com outras pessoas e apontam que esse é um problema recorrente em professores. Alguns sentimentos ligados à Síndrome de Burnout são a exaustão emocional, a despersonalização e a falta de envolvimento com o trabalho.

Codo e Vaques-Menezes (1999) chamam a atenção que o Burnout não deve ser confundido com o stress, já que o Burnout "envolve atitudes e condutas negativas com relação aos usuários, clientes, organização e trabalho; é, assim, uma experiência subjetiva, envolvendo atitudes e sentimentos que vêm acarretar problemas de ordem prática e emocional ao trabalhador e à organização" (Codo \& Vaques-Menezes, 1999, p. 7).

Diante disso, tendo em vista a premência por novas configurações educacionais, suscitadas pela busca de uma educação inclusiva, o olhar sobre os aspectos relacionados à saúde mental dos professores torna-se indispensável, principalmente por estes se constituírem como pilares fundamentais para o alcance da aprendizagem do PAEE. Neste sentido, este trabalho objetivou analisar os trabalhos que investigam a relação entre o mal-estar docente e a inclusão dos alunos público-alvo da educação especial.

\section{Metodologia}

Este trabalho caracteriza-se como uma pesquisa bibliográfica de abordagem qualitativa. De acordo com Goldenberg (2004), as pesquisas de abordagem qualitativa têm por característica o detalhamento de situações, a fim de se entender os indivíduos envolvidos na pesquisa, sendo que estes dados não podem ser padronizados como são os dados quantitativos. Já no que se refere à pesquisa bibliográfica, Severino (2017) discorre que esta se realiza a partir do trabalho com documentos já disponíveis, sendo estes materiais resultantes de pesquisas outrora realizadas, tais como teses, dissertações e artigos científicos.

Este trabalho também apresenta elementos da pesquisa do tipo estado da arte. Segundo Romanowski e Ens (2006), as pesquisas do tipo estado da arte trazem uma grande contribuição teórica para um determinado campo do conhecimento, já que se propõe a encontrar aportes teóricos significativos sobre o tema em questão, além de pontuar restrições sobre o campo em que a pesquisa se encontra, apontar lacunas, bem como inovações sobre aquele tema.

Neste tipo de pesquisa, a análise de teses de doutorado e dissertações de mestrado é destacada, isso porque estes materiais podem fornecer um detalhamento sobre os quadros teórico-metodológicos utilizados pelos pesquisadores, assim como evidenciar detalhes dos resultados obtidos. O fato desses materiais terem passado pela "validação" por pares da comunidade científica da área que, por sua vez, analisa aspectos como a originalidade e a consistência dos estudos, acentua a relevância de investigações sobre tais documentos.

Reconhecendo as oportunidades advindas do estudo das teses e dissertações, esta pesquisa buscou mapear trabalhos que abordam o tema do mal-estar docente relacionado à inclusão de alunos PAEE no catálogo de teses e dissertações da CAPES. O catálogo de teses e dissertações (CTD) da CAPES é uma plataforma que tem por objetivo facilitar o acesso à teses e dissertações de programas de pós-graduação do Brasil (CAPES, 2019).

Assim, para a pesquisa dentro do CTD da CAPES, decidiu-se por utilizar os buscadores "mal-estar docente", "sofrimento psíquico" e "síndrome de Burnout" combinados, por meio do operador booleano "AND", com os seguintes 
buscadores: "inclusão escolar", "educação inclusiva", "educação especial”, "TEA", "aluno surdo", "aluno cego", "aluno com altas habilidades/superdotação" e "aluno com deficiência".

No decorrer da pesquisa, acrescentou-se mais um buscador que foi "sofrimento psíquico docente", pois apenas "sofrimento psíquico" mostrou-se abrangente, haja vista que os resultados apresentaram-se, em sua maioria, relacionados ao sofrimento discente. Outro buscador também foi acrescentado à "síndrome de Burnout", que foi a palavra "professores", de modo a se especificar que a palavra-chave "síndrome de Burnout" deveria ser relacionada a docentes e não a trabalhadores de maneira geral.

Cabe lembrar que, para a realização das buscas no CTD da CAPES, não houve restrição do período temporal, de modo a fornecer informações sobre o desenvolvimento desta área de investigação ao longo dos anos. Além disso, todas as 27 buscas foram realizadas entre os meses de agosto e setembro de 2021.

No total, foram encontrados 45 trabalhos, sendo 34 dissertações de mestrado e 11 teses de doutorado. Com isso, foram definidos os critérios de seleção, exclusão ou dúvida para os trabalhos: critério de seleção - trabalhos que tratem do mal-estar, sofrimento psíquico ou síndrome de Burnout de docentes relacionados à inclusão de alunos PAEE; critério de exclusão trabalhos que não tratem do mal-estar, sofrimento psíquico ou síndrome de Burnout de docentes ou que não o relacionam com a inclusão de alunos PAEE; e, critério de dúvida - trabalhos que durante a leitura do título e/ou resumos não deixaram explícito a abordagem do mal-estar docente relacionada à inclusão de alunos PAEE.

Com os critérios definidos e após a leitura atenta dos títulos e resumos, chegou-se ao número de nove trabalhos incluídos, sendo que cabe mencionar que dois desses nove trabalhos apareceram de forma repetida nos buscadores, portanto, sete trabalhos incluídos; 34 trabalhos excluídos, sendo que também dois apareceram repetidos, portanto, 32 trabalhos excluídos e dois trabalhos entraram no critério de dúvida. Além disso, outra informação que vale chamar a atenção é que, dentro dos trabalhos excluídos, quatro trabalhos não foram encontrados, nem no catálogo da CAPES e nem no catálogo de suas respectivas instituições de ensino superior (IES).

Com isso, foi necessário que se fizesse a leitura por completo dos trabalhos que entraram no critério de dúvida, os quais foram nomeados como CR1 e CR2 (critério dúvida 1 e critério dúvida 2). Com relação ao trabalho CR1, ao realizar a leitura completa do trabalho, percebeu-se que o trabalho fazia referência ao despreparo de professores que trabalham com a inclusão de alunos PAEE, mas não tratava especificamente do sofrimento psíquico desses docentes. Portanto, esse trabalho foi excluído. Sobre o trabalho CR2, o critério de dúvida foi estabelecido a partir da realização da leitura de seu resumo, porém, ao realizar a busca na internet pelo trabalho completo não foi possível encontrá-lo. Dessa forma, o trabalho CR2 também foi classificado como excluído.

Com os sete trabalhos selecionados, fez-se necessário a leitura completa dos trabalhos para a sistematização e análise dos dados. A apresentação dos resultados obtidos a partir da análise dos trabalhos selecionados encontra-se no item a seguir.

\section{Resultados e Discussão}

\subsection{Caracterização dos Trabalhos}

Dentre as análises dos trabalhos selecionados é apresentada, inicialmente, uma caracterização. Na Tabela 1 encontram-se os sete trabalhos selecionados, com seus respectivos títulos, autores(as), ano em que foram publicados, instituição de origem e se referem-se a teses ou dissertações. Ainda nesta seção, são apresentados quais referenciais teóricos e procedimentos metodológicos foram utilizados nas pesquisas. 
Tabela 1. Caracterização inicial dos trabalhos selecionados.

\begin{tabular}{|c|c|c|c|c|c|}
\hline Trabalho & Título & Autor(a) & Instituição & Ano & $\begin{array}{c}\text { Tese ou } \\
\text { Dissertação }\end{array}$ \\
\hline 1 & $\begin{array}{c}\text { Diversidade e adversidades na escola: queixas e } \\
\text { conflitos de professores frente à educação } \\
\text { inclusiva }\end{array}$ & $\begin{array}{l}\text { Claudia Dias } \\
\text { Prioste }\end{array}$ & $\begin{array}{l}\text { Universidade de São } \\
\text { Paulo }\end{array}$ & 2006 & Dissertação \\
\hline 2 & $\begin{array}{l}\text { A escuta na escola inclusiva: saberes e sabores } \\
\text { do mal-estar docente. }\end{array}$ & $\begin{array}{l}\text { Adriana Pereira } \\
\text { Bomfim }\end{array}$ & $\begin{array}{l}\text { Universidade de } \\
\text { Brasília }\end{array}$ & 2008 & Dissertação \\
\hline 3 & $\begin{array}{c}\text { Desenvolvimento de um programa de } \\
\text { enfrentamento da Síndrome de Burnout e } \\
\text { análise dos seus efeitos em professores que } \\
\text { atuam no processo de inclusão }\end{array}$ & $\begin{array}{l}\text { Gisele Cristine } \\
\text { Tenório de } \\
\text { Machado Levy }\end{array}$ & $\begin{array}{l}\text { Universidade do } \\
\text { Estado do Rio de } \\
\text { Janeiro }\end{array}$ & 2011 & Tese \\
\hline 4 & $\begin{array}{c}\text { Trabalho docente/saúde autopercebida das } \\
\text { professoras dos centros de ensino de educação } \\
\text { especial do Maranhão }\end{array}$ & $\begin{array}{l}\text { Creuza Maria } \\
\text { Costa Lázaro }\end{array}$ & $\begin{array}{l}\text { Universidade } \\
\text { Federal do } \\
\text { Maranhão }\end{array}$ & 2013 & Dissertação \\
\hline 5 & $\begin{array}{l}\text { Burnout docente no trabalho com a inclusão de } \\
\text { alunos com necessidades educacionais especiais }\end{array}$ & $\begin{array}{l}\text { Evandir Bueno } \\
\text { Barasuol }\end{array}$ & $\begin{array}{l}\text { Universidade } \\
\text { Federal de Santa } \\
\text { Maria }\end{array}$ & 2004 & Dissertação \\
\hline 6 & $\begin{array}{l}\text { Identidades do professor de educação especial } \\
\text { no contexto de Maceió-Alagoas }\end{array}$ & $\begin{array}{l}\text { Elisangela Leal } \\
\text { de Oliveira } \\
\text { Mercado }\end{array}$ & $\begin{array}{l}\text { Universidade } \\
\text { Federal do Alagoas }\end{array}$ & 2016 & Tese \\
\hline 7 & $\begin{array}{l}\text { A Síndrome de Burnout e o Trabalho na } \\
\text { Educação Especial: um olhar sobre as } \\
\text { percepções dos educadores }\end{array}$ & $\begin{array}{l}\text { Geisa Letícia } \\
\text { Kempfer Böck }\end{array}$ & $\begin{array}{l}\text { Universidade } \\
\text { Federal de Santa } \\
\text { Catarina }\end{array}$ & 2004 & Dissertação \\
\hline
\end{tabular}

Fonte: Autores.

Apesar do CTD da CAPES não esgotar a produção na área, é possível destacar, a partir dos dados apresentados na Tabela 1, que ainda existem poucas investigações acerca do mal-estar docente frente às demandas postas pela perspectiva da educação inclusiva. Percebe-se ainda, pela distribuição temporal dos trabalhos presente na Figura 1 que, mesmo com a quantidade crescente de matrículas dos alunos PAEE nas escolas ao longo dos anos (Brasil, 2021), este fator não tem suscitado o expressivo interesse por este tema de investigação, principalmente porque desde o ano de 2016, o CTD não evidenciou nenhuma outra produção com o foco especificado.

Figura 1. Distribuição temporal dos trabalhos mapeados.

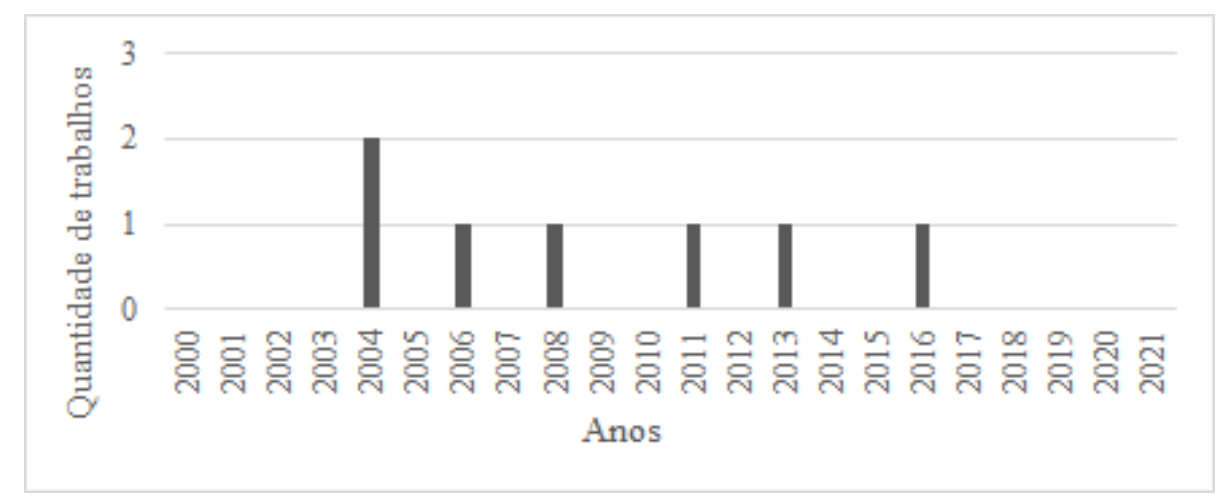

Fonte: Autores.

No que concerne às produções, observa-se que cinco são dissertações de mestrado e apenas duas são teses de doutorado. Com relação aos programas de pós-graduação, percebe-se que apenas um trabalho não é procedente de um programa de pós-graduação em Educação, e sim, advindo de um programa de pós-graduação em Políticas Públicas e Formação Humana. Destaca-se ainda que todas as produções foram provenientes de IES públicas do país, o que enfatiza a importância dessas instituições na produção do conhecimento. 
Ainda na intenção de caracterizar os trabalhos, foram observados que dois dos trabalhos selecionados estão na região Sudeste do Brasil, um trabalho está na região Centro-Oeste, dois trabalhos estão na região Nordeste e dois trabalhos estão na região Sul. Dos trabalhos da região Sudeste, um se localiza na cidade de São Paulo (SP) e o outro na cidade do Rio de Janeiro (RJ); o trabalho da região Centro-Oeste foi realizado em Brasília (DF); dos trabalhos da região Nordeste, um é de São Luís (MA) e o outro de Maceió (AL) e, por fim, dos trabalhos da região Sul, um se encontra em Santa Maria (RS) e o outro em Florianópolis (SC). Desta forma, com exceção da região Norte do Brasil, todas as outras regiões foram representadas neste mapeamento.

Acerca dos procedimentos metodológicos adotados nas produções, a Tabela 2 apresenta uma síntese dos aspectos relacionados à abordagem das pesquisas, aos participantes e aos instrumentos para coletas dos dados.

Tabela 2. Procedimentos metodológicos utilizados nos trabalhos.

\begin{tabular}{|c|c|c|c|c|}
\hline Trabalhos & $\begin{array}{c}\text { Abordagem e tipo de } \\
\text { pesquisa }\end{array}$ & Instrumentos de coleta de dados & Participantes & Contexto de estudo \\
\hline $\begin{array}{l}\text { Prioste } \\
(2006)\end{array}$ & $\begin{array}{c}\text { Qualitativa/ } \\
\text { pesquisa de campo }\end{array}$ & Debates colaborativos e relatos de caso & $\begin{array}{l}26 \text { professores da } \\
\text { classe regular }\end{array}$ & $\begin{array}{l}\text { Escola pública com } \\
\text { alunos com deficiência } \\
\text { em classe comuns e } \\
\text { classes especiais }\end{array}$ \\
\hline $\begin{array}{l}\text { Bomfim } \\
(2008)\end{array}$ & $\begin{array}{l}\text { Qualitativa/ } \\
\text { pesquisa de campo }\end{array}$ & $\begin{array}{l}\text { Memórias de forma escrita, } \\
\text { entrevista semi-estruturada, grupos de } \\
\text { escuta, questionários, documentos e } \\
\text { notas de campo }\end{array}$ & $\begin{array}{l}\text { Cinco professoras } \\
\text { da classe regular }\end{array}$ & $\begin{array}{l}\text { Escola estadual pública } \\
\text { com alunos com } \\
\text { deficiência em classes } \\
\text { comuns }\end{array}$ \\
\hline Levy (2011) & Qualitativa/ pesquisa-ação & $\begin{array}{c}\text { Instrumento CBP - Cuestionário de } \\
\text { Burnout } \\
\text { do Profesorado, } \\
\text { ISSL - Inventário de Sintomas de Stress } \\
\text { para Adultos de Lipp, } \\
\text { Inventário sociodemográfico, } \\
\text { relato verbal e gravações do programa }\end{array}$ & $\begin{array}{l}\text { Sete professoras da } \\
\text { educação especial }\end{array}$ & $\begin{array}{c}\text { Escola da rede pública em } \\
\text { que a maioria dos alunos } \\
\text { têm deficiência }\end{array}$ \\
\hline $\begin{array}{l}\text { Lázaro } \\
\text { (2013) }\end{array}$ & $\begin{array}{l}\text { Quali-quantitativa/pesquisa } \\
\text { bibliográfica e de campo }\end{array}$ & $\begin{array}{c}\text { Entrevista semiestruturadas, } \\
\text { documentos, questionário genérico de } \\
\text { avaliação validada pela qualidade de } \\
\text { vida: "Medical Outcomes Study } 36 \\
\text { Short-From Hekth Survey (SF-36)" }\end{array}$ & $\begin{array}{l}16 \text { professoras da } \\
\text { educação especial }\end{array}$ & $\begin{array}{l}\text { Dois centros de ensino de } \\
\text { educação especial }\end{array}$ \\
\hline $\begin{array}{c}\text { Barasuol } \\
(2004)\end{array}$ & Quantitativa & $\begin{array}{l}\text { Inventário MBI - Maslach Bournout } \\
\text { Inventory }\end{array}$ & $\begin{array}{l}39 \text { professores da } \\
\text { classe comum }\end{array}$ & $\begin{array}{l}\text { Nove escolas da rede } \\
\text { comum de ensino com } \\
\text { alunos NEE incluídos }\end{array}$ \\
\hline Böck (2004) & $\begin{array}{l}\text { Qualitativa/ pesquisa de } \\
\text { campo }\end{array}$ & Questionário Escala Maslach e entrevista & $\begin{array}{l}22 \text { professores da } \\
\text { educação especial; } \\
\text { Um membro da } \\
\text { diretoria }\end{array}$ & $\begin{array}{l}\text { Instituição de ensino } \\
\text { especial }\end{array}$ \\
\hline $\begin{array}{c}\text { Mercado } \\
(2016)\end{array}$ & $\begin{array}{l}\text { Qualitativa/ pesquisa de } \\
\text { campo }\end{array}$ & $\begin{array}{l}\text { História oral, método biográfico, } \\
\text { entrevista narrativa e documentos }\end{array}$ & $\begin{array}{l}\text { Três professoras } \\
\text { das salas de } \\
\text { recursos }\end{array}$ & $\begin{array}{c}\text { Três escolas regulares } \\
\text { com alunos PAEE } \\
\text { matriculados }\end{array}$ \\
\hline
\end{tabular}

Fonte: Autores.

A partir dos dados dispostos na Tabela 2, é possível observar que foram investigados profissionais que trabalham em diferentes organizações educacionais pensadas para a educação dos alunos PAEE, sendo eles: professores de educação especial que atuam em instituições especiais, professores de salas de recursos que atuam em escolas regulares e professores da classe comum que atuam em escolas regulares. Cabe lembrar que antes do movimento em prol da educação inclusiva, as instituições de educação especial acomodavam a maioria das matrículas dos alunos PAEE. Foi no início dos anos 2000, com o investimento do governo em políticas públicas de inclusão escolar, por meio da implantação do AEE em SRM, que houve um 
aumento significativo e contínuo das matrículas desses alunos nas classes comuns do ensino regular (Mendes, 2019). Assim, desde o ano de 2004, as instituições de educação especial assumem uma posição secundária na escolarização desses alunos, o que pode ser expresso nos dados do Censo da Educação Básica de 2020, os quais evidenciaram que, do total de matrículas dos alunos PAEE de quatro a 17 anos, apenas 6,7\% destas matrículas são de alunos que frequentam classes especiais exclusivas (Brasil, 2021).

Outro aspecto a ser destacado diante dos dados apresentados na Tabela 2 refere-se às abordagens de pesquisa. Observa-se que a maioria das produções utiliza da abordagem qualitativa, juntamente com procedimentos de pesquisa que permitiram a coleta dos dados por meio do contato com os participantes investigados, nas próprias condições naturais em que ocorriam os fenômenos, sem a intervenção do pesquisador. Embora os trabalhos não tenham sido nomeados, Severino (2017) descreve esse tipo de procedimento de pesquisa como "pesquisa de campo".

No que tange aos procedimentos para coleta de dados, observa-se que a maioria das pesquisas utilizou instrumentos que permitiram uma aproximação com os investigados, utilizando-se de recursos como entrevistas, história oral, debates, entre outros. Mercado (2016), por exemplo, considerou a importância de valorizar a voz dos professores que trabalham com os alunos PAEE, indo além da aplicação de questionários. Ao mesmo tempo, Böck (2004), que realizou a entrevista apenas com a diretoria, fazendo o uso do questionário Escala Maslach com os professores, concluiu seu estudo apontando que este instrumento, por si só, impediu uma compreensão aprofundada das questões relacionadas à saúde mental dos professores, indicando, desta forma, a necessidade de instrumentos que permitam um contato mais intenso com a rotina de trabalho dos participantes.

Nesta direção, tendo em vista os inúmeros problemas vivenciados pela educação brasileira, Lüdke e André (2020, p. 10) sinalizam que,

Esses problemas, pela sua natureza específica, requerem técnicas de estudo também especialmente adequadas. Em lugar dos questionários aplicados a grandes amostras, ou dos coeficientes de correlação, típicos das análises experimentais, são utilizadas mais frequentemente neste novo tipo de estudo a observação participante, que cola o pesquisador à realidade estudada; a entrevista, que permite o maior aprofundamento das informações obtidas; e a análise documental, que complementa os dados obtidos através da observação e da entrevista e que aponta novos aspectos da realidade pesquisada.

Com relação aos referenciais teóricos utilizados, as pesquisas se apoiaram em diferentes bases. Assim, na Tabela 3, são apresentados quais foram os referenciais teóricos utilizados em cada um dos trabalhos, sendo que, alguns trabalhos utilizaram aportes teóricos variados e, apenas dois trabalhos utilizaram referenciais teóricos semelhantes que, no caso, foi a psicanálise de Freud. 
Tabela 3. Referenciais teóricos utilizados nos trabalhos.

\begin{tabular}{|c|c|}
\hline Trabalhos & Referencial teórico utilizado \\
\hline Prioste (2006) & Referencial teórico psicanalítico de Freud \\
\hline Bomfim (2008) & Referencial teórico psicanalítico de Freud \\
\hline Levy (2011) & $\begin{array}{l}\text { Referencial teórico variado - estudos que fizessem menção à síndrome de Burnout em professores, ao processo de } \\
\text { inclusão escolar e as técnicas de enfrentamento à síndrome. }\end{array}$ \\
\hline Lázaro (2013) & $\begin{array}{l}\text { Referencial teórico variado - autores que tratassem de temas como o histórico do trabalho, a precarização do } \\
\text { trabalho e seus reflexos no fazer docente, além da relação entre os fatores trabalho, saúde, doença e educação } \\
\text { especial. }\end{array}$ \\
\hline Barasuol (2004) & $\begin{array}{l}\text { Referencial teórico variado - estudos que tratavam da formação de professores, da identidade do professor que } \\
\text { trabalha com alunos com deficiência e também sobre a origem e os caminhos que podem levar à Síndrome de } \\
\text { Burnout. }\end{array}$ \\
\hline Böck (2004) & $\begin{array}{c}\text { Referencial teórico variado - utilizou-se de trabalhos que abordassem as questões que envolvem as condições de } \\
\text { trabalho como o salário, os direitos trabalhistas, o preparo inadequado e os conflitos ideológicos que podem cercar } \\
\text { a profissão dos professores. }\end{array}$ \\
\hline Mercado (2016) & $\begin{array}{l}\text { Referencial teórico variado - A autora utilizou de trabalhos que tratassem enfaticamente sobre os } \\
\text { aspectos que envolvem a formação de professores de Educação Especial. }\end{array}$ \\
\hline
\end{tabular}

Fonte: Autores.

Prioste (2006) e Bomfim (2008) justificaram o uso da psicanálise de Freud pois, através da psicanálise, é possível abrir e priorizar a escuta da voz do professor por meio de uma nova leitura para a educação inclusiva, entendendo o mal-estar a partir dessa perspectiva, em que

[...] possibilita recolocar a dimensão da constituição subjetiva do professor, por meio do resgate da sua trajetória de vida escolar e dos efeitos desta em prática educativa, clarificando as concepções de saber e não-saber, normalidade e patologia, eficiência e deficiência, despertadas a partir da inclusão, bem como reconstruindo a atual concepção de formação docente, centrada na acomodação acrítica, na desvalorização profissional e em supostas verdades idealizadas, que corroboram o estado de mal-estar instalado no ambiente educativo e a posição ocupada pelo professor em todo esse processo (Bomfim, 2008, p. 20).

Além de fazer parte da escuta, percebe-se, por meio do trabalho de Prioste (2006), que a psicanálise também forneceu suporte teórico à pesquisadora para o entendimento sobre como lidar com as angústias, sendo que, nesse caso, a pesquisa aponta para a superação da angústia, tendo ela como base as reproduções narcisísticas. Sendo assim, acredita-se que o referencial teórico da psicanálise de Freud concedeu às duas pesquisas uma base teórica capaz também de analisar pontos distintos, como o porquê do sofrimento, quais são as suas raízes e como é possível enxergar esse sofrimento à luz também da responsabilidade pessoal do professor.

Considera-se que os outros referenciais teóricos adotados serviram de base para a discussão de aspectos teóricos diferentes, já que as metodologias adotadas também foram diferentes. Sendo assim, esses referenciais teóricos puderam fundamentar as discussões nos âmbitos das questões trabalhistas e seus reflexos dentro da profissão docente, bem como os aspectos gerais sobre a educação especial.

Na próxima seção, serão abordados, com base nos resultados e discussões dos trabalhos, o que essas pesquisadoras encontraram sobre mal-estar docente e a inclusão de alunos PAEE.

\subsection{O que os trabalhos dizem sobre Mal-estar docente e Inclusão de alunos PAEE}

Tendo por base a identificação de categorias de análise a posteriori, os temas apresentados serão os seguintes: 1) más condições de trabalho e desvalorização profissional; 2) angústias e frustrações; 3) formação de professores; 4) solução/resposta dada sobre o mal-estar. 
No que concerne à categoria 1 - Más condições de trabalho e desvalorização profissional, é importante destacar que essa categoria envolve escritos dos trabalhos que se referem à más condições de trabalho, falta de valorização econômica, falta de materiais didáticos (que se configuram dentro de uma perspectiva de má condição que não possibilita ao professor realizar o seu trabalho), sobrecarga de trabalho e a má relação com os pais dos alunos (o que também se configura má condição trabalhista, já que, ao nosso ver, uma boa relação entre pais e professores gera uma melhor condição da realização profissional).

Assim, dentre os 7 trabalhos selecionados, todos os trabalhos apresentaram escritos que faziam referência às más condições de trabalho e desvalorização profissional. Destaca-se o escrito de Levy (2011, p.145),

As queixas dos professores que atuam no processo de inclusão referem-se ao elevado número de alunos em sala de aula, ao acúmulo de funções, à atenção dedicada aos pais dos alunos, à revisão curricular nos cursos de Educação, à ausência de capacitação especializada, às carências de recursos físicos para o atendimento do aluno com necessidades educativas especiais, dentre outras desconformidades.

O trabalho de Böck (2004) reforça a questão salarial, já que o baixo salário leva os professores a aumentarem a sua carga horária de trabalho na intenção de aumentar a sua renda. Dessa forma, entende-se que dois motivos pertencentes à esta categoria estão interligados: a questão salarial e a carga horária excessiva, ambos com grande potencial para geração de sofrimento nesses docentes. Nesse cenário, a autora apresenta uma análise importante que faz menção à negação do sofrimento por parte dos trabalhadores e trabalhadoras quando os motivos do mal-estar são esses. Essa negação do sofrimento, segundo a pesquisadora, tem relação com os escritos de Codo e Marx sobre a classe operária, já que "[...] na "educação especial" todos estão susceptíveis às leis da oferta e da procura bem como da descartabilidade da força de trabalho" (Böck, 2004, p. 85). Sendo assim, nega-se o sofrimento em prol da produção.

Ainda no trabalho de Böck (2004), pode-se relatar a questão da relação entre pais e professores. Como a pesquisa foi realizada em um centro especializado de ensino especial, os sujeitos apontaram que existem muitos conflitos ideológicos entre os pais e os professores, pois muitos responsáveis não possuem a mesma concepção de inclusão que os docentes possuem.

Na pesquisa de Lázaro (2013), as docentes participantes apontaram que, normalmente, dentro do trabalho com alunos PAEE, o ambiente carece de melhores recursos psicopedagógicos, pois estes são imensamente importantes para se fazer um ótimo trabalho. Essa questão está de acordo com o que Prioste (2006) também apresenta, pois para os sujeitos participantes, quando se tem uma boa condição de trabalho, a construção relacional entre os alunos e os professores é intensificada.

No tocante à categoria 2 - Angústias e frustrações, são feitas menções aos escritos dos trabalhos que abordem angústias e frustrações como queixas, vozes silenciadas, solidão, abandono, insatisfação, exclusão e exaustão emocional que sejam possivelmente geradas pelo trabalho com alunos PAEE. Dentre os sete trabalhos, pode-se encontrar menção a esses sentimentos em cinco trabalhos (Barasuol, 2004; Böck, 2004; Bomfim, 2008; Mercado, 2016; Prioste, 2006). Prioste (2006) apresenta em seus resultados, escritos sobre os participantes que fazem menção ao fato de que esses professores se sentem abandonados e possuem a sua voz silenciada diante de uma condição de trabalho que não os favorece. Sendo assim, os professores são obrigados a aceitar essa condição imposta e que, além disso, esses professores não possuem contato direto com outros profissionais como psicólogos, psicopedagogos, médicos e fonoaudiólogos, ou seja, dentro dessa perspectiva, esses professores também não possuem nem auxílio emocional e nem pedagógico. A pesquisa de Bomfim (2008) também vai ao encontro quando apresenta que os professores, ao serem abordados para participar da pesquisa, se sentiram muito surpresos ao saber que a pesquisa buscava ouvi-los, o que reflete também uma falta de voz por parte desses docentes.

Destaca-se, neste sentido, os resultados da pesquisa de Ribeiro, Ferraz, Oliveira e Lopes (2019), os quais apontaram que o trabalho desenvolvido pelos professores do AEE, que atendem aos alunos PAEE nas SRM, constitui-se como um 
trabalho solitário e sobrecarregado, isto porque pouca articulação é estabelecida entre estes profissionais e os professores que trabalham nas classes regulares. Diante disso, como forma de resolver tal problemática, os autores apontam a necessidade de mudanças organizacionais e atitudinais no ambiente escolar, de forma que se estabeleça um diálogo e uma troca de saberes mais efetiva entre o corpo docente. Uma possibilidade para esta aproximação, a qual tem apresentado resultados promissores no campo da pesquisa, refere-se a estratégia de organização escolar baseada no ensino colaborativo ou co-ensino, na qual os professores do AEE e os professores da classe comum trabalham em parceria e dividem a responsabilidade pelo processo de ensino e aprendizagem da turma, conforme pode ser evidenciado no trabalho de Costa (2021).

Outro aspecto bastante importante que pode ser um potencial gerador de angústias e frustrações identificado foi o do abandono. Ainda dentro da pesquisa de Bomfim (2008), destaca-se a fala de uma das participantes da pesquisa:

"[...] tenho assumido um lugar irresponsável diante da inclusão, eu fui jogada nesse esquema, mas eu continuo em sala de aula sem saber o que fazer"; "senti medo... mas não do meu aluno, medo de mim, por não saber, como lidar com ele... me sinto impotente até hoje”. (Bomfim, 2008, p. 218).

Esta fala denuncia um sentimento de abandono, exclusão, desvalorização profissional e, também, de negligência. Esquecimento em se valorizar o que o professor sente em relação ao fazer docente. A pesquisa de Bomfim (2008) permitiu aos sujeitos participantes relatarem, por meio de narrativas, suas memórias da infância. Em muitas narrativas, a autora encontrou relatos que faziam menção às idealizações dos pais desses professores enquanto profissional, isso revelou uma insatisfação profissional que, assim, gera frustrações nesse docente. Essas características da infância, segundo a pesquisa, demonstram muito a forma como esses professores tendem a conduzir o seu fazer docente.

Os dados quantitativos da pesquisa de Barasuol (2004) mostraram que, dos 39 sujeitos pesquisados, oito apresentaram sinais de exaustão emocional, despersonalização e falta de realização profissional; dez professoras indicavam apresentar sinais de desgaste emocional e, dez mostraram-se pouco realizados profissionalmente. Na pesquisa de Böck (2004), 49\% dos sujeitos pesquisados mostraram sentir-se frustrados com seu trabalho, o que, para a autora, pode ter relação com o fato de que na educação especial os resultados dos trabalhos dos professores serem mais demorados, quando comparados aos do ensino regular. Além disso, esses professores sentem-se inseguros com seus trabalhos, pois possuem incertezas quanto à permanência no serviço. Assim, esses professores não conseguem dar continuidade ao seu trabalho pedagógico, nem mesmo avaliar o progresso dos seus alunos.

Por fim, é importante enfatizar que dentre os dois trabalhos que não entraram nessa categoria, (Lázaro, 2013; Levy, 2011) percebe-se que as justificativas ligadas à não presença de angústias e frustrações se deu porque essas pesquisas foram realizadas em escolas especiais, e não em escolas comuns. Evidenciou-se essa questão, principalmente, porque Lázaro (2013) entende que, se a sua pesquisa tivesse sido realizada em uma escola comum, a realidade sobre o sofrimento mental seria outra.

A terceira categoria refere-se à Formação de professores. Essa categoria mostrou-se uma constante em todos os sete trabalhos. A falta de preparo refere-se à formação desses professores, sendo ela, formação inicial acadêmica e formação continuada. Independentemente do local de atuação, se classe especial, regular ou sala de recursos, a queixa acerca do despreparo para atuar com o aluno PAEE sobressaiu em todos os trabalhos, resultados que também podem ser evidenciados em pesquisas como as de Oliveira e Prieto (2020) e Pasian, Mendes e Cia (2017).

Na pesquisa de Prioste (2006), quando perguntado aos 26 indivíduos participantes sobre alguns cursos de educação inclusiva que são ofertados pelo Estado, apenas "dois ou três professores disseram ter participado" (Prioste, 2006, p. 130). A falta de preparo foi uma queixa recorrente entre os participantes, mas, corroboramos com Prioste (2006) quando esta entende que existe uma diferença entre se queixar e o desejar ser preparado para isso e que, muitas vezes, os professores se apegam a 
queixa e são assim, aprisionados num "gozo mortífero, o gozo da queixa" (Prioste, 2006, p. 129). Sendo assim, os docentes se esquecem e deixam de possuir um sentimento de investimento nesses alunos, o que obviamente os distancia.

Quando Bomfim (2008) apresenta dados que fazem referência à falta de preparo, a autora apresenta uma crítica que é feita pelos participantes quanto aos cursos de capacitação e diz que, normalmente, esses cursos apresentam o tema da inclusão "preso a soluções mágicas, com concepções arcaicas e segmentadas do conhecimento, recheadas por ideais inatingíveis" (Bomfim, 2008, p.210) e ainda, acrescenta que esse é um processo que, muitas vezes, fabrica um profissional sob medida e que deixa de considerar o lado humano desses professores.

Apesar da pesquisa de Lázaro (2013) ter sido realizada numa instituição especializada para o PAEE, as professoras falaram sobre as escolas públicas de Maranhão (que não é o centro educacional em que elas trabalham). A opinião das professoras sobre a educação inclusiva nas escolas públicas é a de que é ineficaz, e, na sua maioria, possui relação com a falta de preparo dos professores nas salas de ensino regular, além da falta de acessibilidade.

Barasuol (2004) realizou sua pesquisa com 39 docentes que atuavam no ensino já há muitos anos, e, por isso, entendeu que pelo tempo de atuação provavelmente elas não tiveram em sua formação conhecimentos que abordavam a educação inclusiva. Assim, a pesquisa entende que é necessário que o professor não só atualize seus conhecimentos como também "renuncie a conteúdos e a um saber que vinha sendo de seu domínio durante anos" (Barasuol, 2004, p. 77), pois, "se ele resistir a essas mudanças, provavelmente será questionado, e, ao se ver enredado nesse emaranhado de dúvidas internas e demandas do contexto escolar, poderá desenvolver sentimentos de mal-estar que levem ao Burnout” (Barasuol, 2004, p.77). Outro potencial que agrega dentro dessa perspectiva é o preparo apenas em nível de magistério ou profissionais cujos cursos não capacitaram os docentes devidamente (Böck, 2004).

De acordo com Carmo, Fumes, Mercado e Magalhães (2019), o que contribui para as insatisfações dos profissionais que atuam com os alunos PAEE no que se refere ao seu processo formativo, é o fato de as políticas públicas de inclusão no Brasil terem priorizado o acesso de tais alunos às escolas regulares, enquanto que a formação de professores assume uma posição secundária nos documentos oficiais, sendo que, muitas vezes, sequer é citada nestas políticas.

Segundo estes autores, a formação de professores para trabalhar com o PAEE apresenta-se como um modelo ineficiente, haja vista que, no que tange à formação de professores para atuar na educação regular, a iniciativa existente - e reforçada atualmente por meio das diretrizes nacionais (Brasil, 2015; 2019) - corresponde à inserção da temática sobre a educação inclusiva nos currículos dos cursos de licenciatura. Já no que se refere a formação de professores especialistas, esta tem se configurado basicamente por meio da formação continuada, ofertada pela modalidade à de Educação à Distância (EAD) (Carmo, et al, 2019), com poucas possibilidades de formação inicial em licenciatura em Educação Especial na modalidade presencial em território brasileiro.

Soma-se à essa problemática o fato de, segundo Mercado (2016), os cursos de formação continuada constituirem-se como uma formação de curta duração, que promovem, em grande parte das vezes, uma "[...] formação continuada com características mais operacional/técnica do que profissional, por meio de um modelo formativo fundado numa perspectiva centrada nas causas física-neurológicas mentais do sujeito com deficiência e na procura de respostas em teorias médicas e psicopedagógicas" (Mercado, 2016, p. 266). Segundo a autora, estes cursos pouco contribuem para o fazer pedagógico destes profissionais e pouco orientam no sentido de colaborar com os professores da classe regular.

Este cenário expressa a crítica realizada por Nepomoceno (2020), a qual discute que, embora as políticas educacionais que trazem a inclusão em destaque teçam discursos em defesa de uma educação inclusiva, equitativa e de qualidade para todos os alunos, poucas condições e subsídios concretos têm sido oferecidos para que ocorra a materialização destes ideais nos contextos educacionais brasileiros. 
Foram selecionados para a quarta categoria trechos dos trabalhos que fizessem menção a Soluções e/ou respostas que os autores propuseram em decorrência do mal-estar dos educadores em relação aos seus alunos PAEE. Essas informações foram coletadas, pois acredita-se ser importante ao leitor entender que, em virtude de algumas queixas, para elas, são encontradas respostas que podem explicar esse sofrimento e, além disso, para as respostas, são encontradas soluções e ações que podem amenizar o sofrimento desse professor.

Uma das respostas encontradas foi dada por Prioste (2006), a qual apresenta que, muitas vezes, o olhar dos professores ao aluno PAEE é como um olhar para o desconhecido, para o estranho e, por isso, na intenção de amenizar esse sofrimento, a autora sugere que é necessário que esses docentes tornem esse estranho um pouco mais familiar. A autora apresenta a explicação da angústia baseada na perspectiva de Lacan em que angústia e narcisismo estão ligados: "Lacan relaciona angústia a um impedimento, movimento que se detém por uma armadilha, a armadilha narcísica. Angústia e narcisismo caminham juntos. Narcisismo implica em fixação na própria imagem especular” (Prioste, 2006, p. 148).

Sendo assim, do ponto de vista apresentado por Prioste (2006), baseado em Lacan, a angústia não é para ser tratada e sim, para ser atravessada, e uma das maneiras de se atravessar essa angústia é a escuta. Ao fato de ser escutado, o professor pode, então, se auto escutar. É aqui que se cria um ambiente de exposição dos seus temores, anseios e dúvidas. Porém, ainda assim, dar voz não basta. É necessário que esse professor se responsabilize por sua própria busca pelo gozo, entendendo que a mudança também faz parte do processo. É importante que ao escutar-se, o sujeito aja.

Nessa perspectiva, a pesquisa de Barasuol (2004) também vai ao encontro de tal ideia, e a pesquisadora diz que é extremamente necessário que o professor reconheça quais são seus verdadeiros anseios, desejos para com o trabalho com alunos PAEE, ou seja, que esse docente se auto avalie em termos de constante mudança e atualização de seus conhecimentos.

Ainda dentro da noção das reproduções narcisistas, Bomfim (2008) também apresenta que, muitas vezes, os professores se apegam às suas satisfações narcisistas "com uma educação voltada à satisfação dos ideais narcísicos, a criança é levada a identificar-se, sobretudo, com belas imagens, que não agridem o seu narcisismo" (Bomfim, 2008, p. 213).

Dessa forma, essa imagem cria uma relação imaginária entre o professor e o aluno, e, nesse caso, o aluno não atende as idealizações e expectativas do professor. Porém, entende-se que o processo de inclusão do aluno com deficiência busca romper e redefinir esse ideal de perfeição, em que o aluno é colocado como tendo um perfil ideal e que está dentro de uma norma. Esta compreensão, a qual está relacionada ao modelo médico de deficiência, deve ser continuadamente superada, haja vista que "a concepção de deficiência como variação do normal da espécie humana foi uma criação discursiva do século XVIII" (Diniz, 2012, p. 8). Cabe lembrar ainda que “a anormalidade é um julgamento estético e, portanto, um valor moral sobre os estilos de vida. Há quem considere que um corpo cego é algo trágico, mas há também quem considere que essa é uma entre várias possibilidades para a existência humana" (Diniz, 2012, p. 8).

Tratando-se de algumas ações, Levy (2011) apresenta que uma das ações necessárias é a criação de programas de intervenção para o controle ou a prevenção da Síndrome de Burnout. Böck (2004) também acredita que seria necessário criar métodos de aproximação da rotina desses professores para conhecer suas dificuldades, angústias e desejos. Conhecendo a si, é necessário que esse professor tome uma decisão, uma escolha frente à diversidade. E, quando se fala de inclusão, não há como “andar para trás”, essa não é uma "moda passageira” (Diniz \& Itaborahy Ferraz, 2015). Portanto, quando o professor decide investir em si, entendendo seus anseios e angústias, ele é capaz também de investir em sua formação e pode construir a sua identidade, pois nela encontra-se um lugar de lutas, conflitos, mas também um lugar de maneiras de ser e estar na vida (Diniz \& Itaborahy Ferraz, 2015). Sendo assim, “descobrir os motivos dessas escolhas, entendê-las, analisá-las à luz de uma reflexão colada aos processos históricos e sociais da humanidade deveria ser uma das tarefas do(a) educador(a)" (Diniz \& Itaborahy Ferraz, 2015, p.187). 
É importante que o professor se questione, entenda qual é a sua posição, qual a sua motivação frente ao aluno PAEE e, além disso, seja crítico com as respostas que encontrar. Será que suas respostas estão pautadas num ideal padronizado de alunos? Qual é a sua posição frente à diversidade em sala de aula? Essas análises podem ser norteadoras para o entendimento do sofrimento. Entende-se que há motivos que foram encontrados nos trabalhos que vão para além da responsabilidade e capacidade do professor em resolver, como o baixo salário, as más condições de trabalho e a falta de materiais didáticopedagógicos. Mas também concordamos que, nenhum desses motivos são culpa dos próprios alunos.

\section{Conclusão}

Entendendo que a escola é um lugar de respeito à diversidade e que não permite a propagação de atitudes discriminatórias, bem como compreendendo que os direitos das pessoas com deficiência são assegurados pela legislação educacional brasileira, conclui-se que este trabalho pôde analisar de forma específica e enfática as contribuições que as dissertações e teses encontradas no CTD da CAPES dizem a respeito do mal-estar docente frente às exigências da inclusão de alunos com PAEE nas escolas. Além disso, este trabalho também pôde mostrar como ainda existem lacunas nas produções acadêmicas acerca do tema e como ainda é necessário que a comunidade acadêmica se preocupe mais com essa discussão, para entender de que forma é possível compreender e ajudar os professores das escolas a superarem suas angústias frente a educação inclusiva.

Destaca-se a importância de se analisar, de forma profunda, os escritos que dizem respeito à formação dos professores, que se apresentou frágil e inconsistente em decorrência das exigências que são impostas pela educação inclusiva. Enfatiza-se, também, que diante das críticas e análises propostas, é necessário que os professores se sintam encorajados a se responsabilizarem pelas atitudes no que diz respeito a suas próprias ações pedagógicas, formação e posicionamento frente a presença de um aluno PAEE em sala.

Acredita-se que este trabalho servirá de apoio teórico para pesquisas futuras no que concerne ao entendimento de que metodologias e referenciais teóricos foram adotados pelas pesquisas até aqui realizadas. Considera-se, ademais, que a educação inclusiva precisa ser ressignificada por parte dos professores. É necessário que professores e gestores se apropriem de laços desprovidos de preconceito e ações narcísicas com seus alunos, e sim, repletas da capacidade de respeito aos direitos dos alunos com deficiência.

Por fim, entende-se que, a partir deste trabalho, pesquisas futuras possam ser realizadas no que se refere ao entendimento de qual é a percepção dos professores das classes regulares de ensino com relação a seus alunos PAEE, bem como pesquisas que se proponham a conhecer qual é a ajuda fornecida a esses professores, entendendo as suas relações com a rede pública de ensino. Além disso, orienta-se que pesquisas futuras analisem como a questão da educação dos alunos PAEE tem se inserido nos cursos de formação dos professores, já que este aspecto é, em grande parte, responsável por percepções negativas dos profissionais no dia-a-dia escolar.

\section{Referências}

Barasuol, E. B. (2004). Burnout docente no trabalho com a inclusão de alunos com necessidades especiais. (Dissertação de Mestrado). Universidade Federal de Santa Maria, Santa Maria, RS, Brasil.

Bastos, M. B., \& Kupfer, M. C. M. (2010). A escuta de professores no trabalho de inclusão escolar de crianças psicóticas e autistas. Estilos da Clínica, 15(1), 116-125. http://pepsic.bvsalud.org/scielo.php?script=sci_arttext\&pid=S1415-71282010000100008

Bock, G. L. K. (2004) A Síndrome de Burnout e o Trabalho na Educação Especial: Um olhar sobre as percepções dos educadores. (Dissertação de Mestrado). Universidade Federal de Santa Catarina. Florianópolis, SC, Brasil.

Bonfim, A. P. (2008). A escuta na escola inclusiva: saberes e sabores do mal-estar docente. (Dissertação de Mestrado). Universidade de Brasília. Brasília, DF, Brasil. 
Brasil. (2008). Decreto $\mathrm{n}^{\mathrm{o}}$ 6.571, de 17 de Setembro de 2008. Diário Oficial da União, Poder Executivo, Brasília, DF. https://www.planalto.gov.br/ccivil_03/_ato2007-2010/2008/decreto/d6571.htm.

Brasil. (2011). Decreto $\mathrm{n}^{\circ}$ 7.611, de 17 de Novembro de 2011. Diário Oficial da União, Poder Executivo, Brasília, DF. http://www.planalto.gov.br/ccivil_03/_ato2011-2014/2011/decreto/d7611.htm.

Brasil. (2021). Instituto Nacional de Estudos e Pesquisas Educacionais Anísio Teixeira (Inep). Censo da Educação Básica 2020: Resumo Técnico. Brasília: Inep. http://portal.inep.gov.br/informacao-da-publicacao/-/asset_publisher/6JYIsGMAMkW1/document/id/6993007.

Brasil. (2008). Ministério da Educação. Secretaria de Educação Continuada, Alfabetização, Diversidade e Inclusão. Política Nacional de Educação Especial na Perspectiva da Educação Inclusiva. Brasília, DF. http://portal.mec.gov.br/arquivos/pdf/politicaeducespecial.pdf.

Brasil. (2015). Resolução CNE/CP No 2, de 1 de julho de 2015. Define as Diretrizes Curriculares Nacionais para a formação inicial em nível superior (cursos de licenciatura, cursos de formação pedagógica para graduados e cursos de segunda licenciatura) e para a formação continuada. Brasília, DF. http://portal.mec.gov.br/docman/agosto-2017-pdf/70431-res-cne-cp-002-03072015-pdf/file.

Brasil. (2019). Resolução CNE/CP No 2, de 20 de dezembro de 2019. Define as Diretrizes Curriculares Nacionais para a Formação Inicial de Professores para a Educação Básica e institui a Base Nacional Comum para a Formação Inicial de Professores da Educação Básica (BNC-Formação). http://portal.mec.gov.br/docman/dezembro-2019-pdf/135951-rcp002-19/file.

Carmo, B. C. M., Fumes, N. L. F., Mercado, E. L. O., \& Magalhães, L. O. de. R. (2019). Políticas públicas educacionais e formação de professores: convergências e distanciamentos na área de Educação Especial. Revista Educação Especial, 32(0), 1-28. doi:10.5902/1984686X39223

Carvalho, R. E. (2019). Educação Inclusiva: com os pingos nos "is".: Mediação.

Codo, W., \& Vasques-Menezes, I. (1999). O que é Burnout? Educação: carinho e trabalho, 2, 237-254.

Coordenação De Aperfeiçoamento De Pessoal De Nível Superior (2019). CAPES Brasil 1987-2012. https://metadados.capes.gov.br/index.php/catalog/181

Costa, L. G. S. (2021). Estratégias de ensino colaborativo como uma proposta de Atendimento Educacional Especializado - AEE. (Dissertação de mestrado). Universidade Estadual Paulista “Júlio Mesquita Filho", Bauru, SP, Brasil.

Diniz, D. (2012). O que é Deficiência? São Paulo: Brasiliense.

Diniz, M., \& Itaborahy Ferraz, C. (2015). Diferença, diversidade e formação docente: contribuições da psicanálise à discussão da inclusão. Educação, 38(2), 185-192. doi:10.15448/1981-2582.2015.2.20044

Ferreira, N. S. A. (2002). As pesquisas denominadas “estado da arte". Educação \& Sociedade, 23(79). 257-272. https://www.scielo.br/j/es/a/vPsyhSBW4xJT48FfrdCtqfp/?format=pdf\&lang=pt

Francelin, M. M. (2016). Fichamento como método de documentação e estudo. In Tópicos para o ensino de biblioteconomia: volume I (p. 190). ECA-USP. http://www3.eca.usp.br/sites/default/files/form/biblioteca/acervo/producao-academica/002749741.pdf.

Goldenberg, M. (2004). A arte de pesquisar: como fazer pesquisa qualitativa em Ciências Sociais. Record.

Lázaro, C. M. C. (2013). Trabalho docente/saúde autopercebida das professoras dos centros de ensino de Educação Especial do Maranhão. (Dissertação de Mestrado). Universidade do Maranhão, São Luís, MA, Brasil.

Levy, G. C. T. M. (2011). Desenvolvimento de um programa de enfrentamento da Síndrome de Burnout e análise dos seus efeitos em professores que atuam no processo de inclusão na Rede Pública de Ensino. (Tese de Doutorado). Universidade do Estado do Rio de Janeiro, Rio de Janeiro, RJ, Brasil.

Lüdke, M., \& André, M. E. D. A. (2020). Pesquisa em educação: abordagens qualitativas. E.P.U.

Mendes, E. G. (2019). A política de educação inclusiva e o futuro das instituições especializadas no Brasil. Arquivos Analíticos de Políticas Educativas, 27(22), 1-27. doi:10.14507/epaa.27.3167

Mercado, E. L. O. (2016). Identidades do Professor de Educação Especial no Contexto de Maceió-Alagoas. (Tese de Doutorado). Universidade Federal do Alagoas, Maceió, AL, Brasil.

Nepomoceno, T. A. R. (2020). Evolution of public school inclusion policies in Brazil: between theoretical dilemmas and points of tension. Research, Society and Development, 9(9), e805997918. doi:10.33448/rsd-v9i9.7918

Oliveira, A. A. S., \& Prieto, R. G. (2020). Formação de Professores das Salas de Recursos Multifuncionais e Atuação com a Diversidade do Público-Alvo da Educação Especial. Revista Brasileira de Educação Especial, 26(2), 343-360. doi:10.1590/1980-54702020v26e0186

Pasian, M. S., Mendes, E. G., \& Cia, F. (2017). Atendimento educacional especializado: aspectos da formação do professor. Cadernos de Pesquisa, 47(165), 964-981. doi:10.1590/198053144242

Picado, L. (2009). Ser professor: do mal-estar para o bem-estar docente. Psicologia.com.Pt. O Portal dos Psicólogos. 2009. https://www.psicologia.pt/artigos/textos/A0474.pdf

Prioste, C. D. (2006) Diversidades e Adversidades na Escola: queixas e conflitos de professores frente à Educação Inclusiva. (Dissertação de Mestrado) Universidade de São Paulo, São Paulo, SP, Brasil.

Ribeiro, V. M., Ferraz, D. P. A., Oliveira, J. F., \& Lopes, S. M. (2019). The use of the multifunctional resources rooms for science teaching: a study on inclusion. Research, Society and Development, 8(6), 1-21. doi:10.33448/rsd-v8i6.1025 
Research, Society and Development, v. 10, n. 17, e159101724399, 2021

(CC BY 4.0) | ISSN 2525-3409 | DOI: http://dx.doi.org/10.33448/rsd-v10i17.24399

Romanowski, J. P., \& Ens, T. R. (2006). As pesquisas denominadas do tipo "estado da arte" em educação. Diálogo Educ., 6(19), 37-50. https://periodicos.pucpr.br/dialogoeducacional/article/view/24176/22872

Xavier, A., Nunes, A. I. B. L., \& Santos, M. S. (2008). Subjetividade e sofrimento psíquico na formação do Sujeito na Universidade. Revista Mal-estar e Subjetividade. 3(2). 427-451. https://www.redalyc.org/articulo.oa?id=27180208 